\title{
Special issue on responses to the epistemological challenges to indigenous psychologies
}

\author{
Manfusa Shams \\ Department of Science, Regent's College, London, UK
}

\author{
Kwang-Kuo Hwang \\ Department of Psychology, National Taiwan University, Taiwan
}

In the late 1970s, psychologists in many areas of the world began to promote an indigenization movement. In contrast to the usual practice of importing Western paradigms for psychological research, many non-Western researchers began to use local values, concepts and belief systems to study the behavior and mental processes of native people in their own cultural context (Kimand \& Berry, 1993; Kim et al., 2000). They adopted a bottom-up strategy of model building (Kim, 2000) in order to develop a culture-appropriate psychology, or a psychology based on indigenous realities.

This indigenous approach has been criticized by mainstream psychologists who have pointed out that accumulating data with an idiosyncratic approach may not contribute much to the development of scientific psychology (Triandis, 2000). The development of multiple psychologies contradicts the scientific requirement of parsimony (Poortinga, 1999). If every culture develops its own psychology, a kind of ethnocentrism in reverse (Ho, 1988) or a scientific ethnocentrism in a new guise (Poortinga, 1999), would emerge.

The development of indigenous psychologies has progressed to a cross-road. Indigenous psychologists have to face these epistemological challenges and, if they are unable to overcome these epistemological difficulties, indigenization simply becomes a social movement for changing the power structure of academic communities in non-Western countries. Its contribution to the progress of psychology will be doubted and its future development restricted.

Therefore, we invited several distinguished psychologists who are closely involved in the progress of indigenous psychologies to respond to the following issues that surface in recent debates on Indigenous psychologies.

1 What are the epistemological challenges for the development of indigenous psychologies?

2 What are the epistemological strategies to deal with those challenges?

3 What is the best methodology for indigenous psychologists to use to develop a global psychology or universal psychology?

4 What is the nature of the intellectual tension among various indigenous psychologies around the world?

5 What scientific approaches should be taken to further develop indigenous psychologies?

6 How can indigenous psychologies be integrated with mainstream psychology?

The papers in this Special Issue were reviewed by two experts in indigenous psychologies or cultural psychology, and the authors were asked to revise their papers with respect to the comments received. 
The first paper is a response to the epistemological and methodological challenges directed at indigenous psychologists. Hwang advocates a deductive approach based on the philosophy of post-positivism instead of the inductive approach of naïve positivism, which is very popular among indigenous psychologists. Hwang formulates his arguments on the basis of the Western philosophy of science. On the contrary, Kashima proposes the core concepts of 'symbolic self-reflexivity' and argues that a culturally based Asian monistic world view will lead to a social psychology that may overcome certain ontological and epistemological contrasts in Western mainstream psychology.

Shams has proposed an interdisciplinary approach to further develop indigenous psychologies. In particular, she highlights the importance of local knowledge within ethnic or migrant communities in multicultural societies, which is essential for sustaining these communities, especially when they are in opposition to the majority group in society. She argues that attention to issues of local knowledge construction should contribute to a globalized indigenous psychology.

Jackson draws on complexity theory to illustrate how knowledge communities operate by encouraging individuals or groups to explore different regions of the knowledge landscape, and how higher-order characteristics of a system emerge spontaneously from the interactions of its elements. Historical examples of the indigenization of psychology in Canada, Russia and Turkey are provided to support his arguments.

As a whole, Hwang and Kashima address contemporary issues in indigenous psychologies from epistemological and methodological perspectives, while Shams and Jackson adopt interdisciplinary perspectives in their analyses, drawing on relevant theoretical models and frameworks from eco-psychology, cross-cultural and cultural psychology, applied social and community psychology, and organizational culture.

Finally, two commentaries by Poortinga, and Kim and Park provide further clarification for the debate on indigenous psychologies. The paper by Kim and Park not only provides a critique of the four articles, but also an alternative perspective, which, in their view, is most useful for the development of indigenous psychologies. We believe that this Special Issue will definitely contribute significantly to the progress of indigenous psychologies.

\section{References}

Ho, D. Y. F. (1988). Asian psychology: A dialogue on indigenization and beyond. In: A. C. Paranjpe, D. Y. F. Ho \& R. W. Rieber, eds. Asian Contributions to Psychology, pp. 53-77. New York: Praeger.

Kim, U. (2000). Indigenous, cultural, and cross-cultural psychology: A theoretical, conceptual, and epistemological analysis. Asian Journal of Social Psychology, 3, 265-287.

Kim, U. \& Berry, J. (1993). Introduction. In: U. Kim \& J. Berry, eds. Indigenous Cultural Psychologies: Research and Experience in Cultural Context, pp. 1-29. Newbury Park, CA: Sage.

Kim, U., Park, Y. S. \& Park, D. (2000). The challenger of cross-cultural psychology: The role of the indigenous psychologies. Journal of Cross-Cultural Psychology, 3, 63-75.

Poortinga, Y. H. (1999). Do differences in behavior imply a need for different psychologies? Applied Psychology: An International Review, 48, 419-432.

Triandis, H. C. (2000). Dialectics between cultural and cross-cultural psychology. Asian Journal of Social Psychology, 3, 185-195. 